\title{
A internacionalização na perspectiva da educação patrimonial: um projeto no campo da educação musical latino-americana
}

Internationalization from the perspective of Heritage Education: a Latin American Music Education project

Andréia Veber ${ }^{1}$

Universidade Estadual de Maringá -UEM https://orcid.org/0000-0003-2840-6937

Solange Franci Raimundo Yaegashi Universidade Estadual de Maringá - UEM http://orcid.org/0000-0002-7666-7253

Paulina Alejandra Reyes Díaz Universidade Estadual de Maringá - UEM https:/lorcid.org/0000-0002-9236-720X 


\section{Resumo}

Este texto apresenta reflexões emersas da análise das ações de um projeto de internacionalização desenvolvido em parceria entre duas instituições de ensino superior de dois países latino-americanos: Brasil e Chile, entre 2018 e 2019. Tanto as proposições quanto as discussões apresentadas tomaram como fundamento os princípios da educação patrimonial contemporânea e a ideia de internacionalização proposta por Kertz-Welzel (2018). Como resultado, a análise das ações permite dizer que a internacionalização, quando parte de planejamento colaborativo e integrado com as comunidades participantes, se consolida num processo educativo de construção, identificação e valorização de patrimônios que rompem fronteiras, visando à construção de comunidades de práticas artísticas culturalmente sensiveis e mundialmente conectadas.

Palavras-chave: Patrimônio cultural. Práticas artísticas. Projetos internacionais. Arte e educação. Práticas musicais.

\section{Abstract}

This text presents some of the reflections carried out based on the actions of an internationalization project developed in partnership between two higher education institutions from two Latin American countries: Brazil and Chile. The project was developed between the years 2018 and 2019. Both the proposals and the possibilities were based on the principles of Contemporary Heritage Education and the idea of internationalization as proposed by Kertz-Welzel (2018). As a result, an analysis of the actions carried out allows us to say that internationalization, when they start from collaborative planning that emerges from integration with participating communities, is consolidated in an educational process of, identification and appreciation of heritage that break limits, forms the construction of communities culturally related and globally connected artistic practices.

Keywords: Cultural heritage. Artistic practices. International projects. Art education. Musical practices.

1 Doutora em Educação pela Universidade Estadual de Maringá. Mestre em Música - Educação Musical pela Universidade Federal do Rio Grande do Sul. Licenciada em Música pela Universidade do Estado de Santa Catarina. Docente no departamento de Música da Universidade Estadual de Maringá. É integrante do Grupo de Estudos e Pesquisas em Escola, Família e Sociedade (GEPEFS).

2 Pós-Doutora em Psicologia pelo Instituto de Psicologia da Universidade de São Paulo (USP). Doutora e Mestre em Educação pela Universidade Estadual de Campinas (UNICAMP). Graduação em Psicologia pela Universidade Estadual de Maringá (UEM). Docente do Departamento de Teoria e Prática da Educação e do Programa de Pós-Graduação em Educação da Universidade Estadual de Maringá (UEM). Líder do Grupo de Estudos e Pesquisas em Escola, Familia e Sociedade (GEPEFS).

3 Mestranda em Educação na Universidade Estadual de Maringá. Possui graduação em Pedagogia en Educacion Basica, Licenciada en Educacion pela Universidad Austral de Chile (2007). Integrante do Grupo de Estudos e Pesquisas em Escola, Familia e Sociedade (GEPEFS). 


\section{Introdução}

Neste texto são apresentados fundamentos conceituais e análise das ações desenvolvidas no projeto de internacionalização denominado "Patrimônio cultural latino-americano - interface entre música, cultura popular e educação - Chile e Brasil - 2018", desenvolvido em parceria por duas instituições latino-americanas, de ambos os países. O projeto teve como objetivo implementar um programa de residência artística e acadêmica que permitisse reflexão e intercâmbio de conhecimentos e experiências sobre práticas artísticas e educativas favorecendo as discussões sobre patrimônio cultural em contexto latino-americano. Contou com a realização de instâncias acadêmicas, artísticas, formativas e investigativas, concretizadas via programa de internacionalização entre a Universidade Estadual de Maringá (Brasil) e a Universidad de O'Higgins (Chile).

O tema internacionalização e globalização na educação musical é discutido com o intuito de buscar articulações com o campo da educação patrimonial. Essa articulação foi proposta na tese de doutorado intitulada "Educação musical em contexto de internacionalização: representações sociais de professores sobre patrimônio cultural e culturas populares", cujo foco foi tratar de patrimônio cultural e culturas populares nas práticas de educação musical e sua aproximação com o campo da educação patrimonial. Assim, o conjunto conceitual e as discussões aqui trazidas foram baseadas no texto original da tese doutoral de autoria de uma das professoras brasileiras envolvidas no projeto.

Para tratar da internacionalização sob a perspectiva da educação musical, buscamos apoio nos estudos da professora e pesquisadora alemã Alexandra Kertz-Welzel (2018), que defende o desenvolvimento de experiências e pesquisas em âmbito internacional como forma de conhecer distintos contextos educacionais, em especial estudos de realidades ainda pouco pesquisadas. Corroboramos com esse pensamento da autora quando ela argumenta sobre a necessidade de integrar contextos de interação local - já dotados de experiências diversificadas, desde as mais locais às mais globalizadas - oriundos de comunidades globais diversas, envolvendo ações práticas e investigativas que estejam conectadas e atentas à necessidade de criar aquilo que a autora chama de comunidades globais de educação musical culturalmente sensíveis (KERTZ-WELZEL, 2018).

Ao abordar esse tema, a autora se refere especialmente à atenção que julga necessária aos tipos de conhecimento que são valorizados ou subestimados quando se trata de comunidade internacional, atenta para que as trocas e os intercâmbios sejam considerados de maneira igualitária, descartando a hegemonia até então presente em relação às pesquisas desenvolvidas em países europeus ou norte-americanos. Assim, ela alerta para a necessidade de abertura mundial e maior atenção à descentralização das pesquisas em relação aos países mais desenvolvidos.

A educação patrimonial é compreendida neste texto como campo de estudos que tem se dedicado aos processos educacionais que envolvem patrimônio cultural, desde questões conceituais às práticas educativas de seu entorno. 
O texto está organizado em três partes. Na primeira buscamos aprofundar as reflexões sobre internacionalização e suas aproximações com a educação musical, partindo das reflexões de Kertz-Welzel e apresentando outros autores que fundamentaram o projeto em relação ao tema.

Na segunda parte, trazemos uma breve explanação sobre a compreensão adotada no projeto acerca da educação patrimonial. Na terceira parte apresentamos de forma breve as ações e as reflexões advindas da análise realizada posteriormente. Tal análise foi elaborada por meio do estudo das ações desenvolvidas considerando as bases conceituais que regem a implementação da proposta em campo.

Partimos da compreensão de que a música, em todas as suas formas de relação, está no centro das culturas e em nosso cotidiano, integrando nosso patrimônio cultural. Seja compondo, criando ou recriando, a música comporta identidades - individuais e coletivas -, estando também na centralidade de um movimento em constante construção, desconstrução e reconstrução de patrimônios, isso sob o efeito da internacionalização e da globalização presentes nas sociedades contemporâneas.

\section{A internacionalização - aproximações com a educação musical}

Como descrito na introdução deste texto, tratamos da internacionalização e de sua aproximação com o campo da educação musical, partindo das reflexões levantadas por Kertz-Welzel (2018). A autora parte da defesa de um movimento de internacionalização da educação musical que considere a construção ou ampliação do que ela chama de comunidades globais de educação musical culturalmente sensíveis.

Kertz-Welzel (2018) sugere que a internacionalização se processe pela construção de um "ser global" que possa transitar pelos universos musicais e culturais, compreendendo tanto seu papel quanto o significado de cada uma das experiências. A construção desse "ser global" estaria associada a estas comunidades globais de educação musical, considerando tanto a criação de políticas internacionais de educação musical quanto a criação de ambientes de aprendizagem musical que sejam globais.

No que se refere à criação de políticas, defende-se a atuação sólida de uma comunidade de educação musical global diante das proposições sobre as mudanças advindas da Organização das Nações Unidas para Educação, Ciência e Cultura (Unesco), como órgão mundial de influência direta nas políticas para educação e cultura. Entendemos que a participação dessa comunidade seria mais bem demarcada se tivéssemos mais fortemente constituída uma comunidade global de educação musical, como forma de possibilitar uma participação política mais efetiva e atenta às demandas do mundo, com olhares sensíveis para as diversidades de culturas das sociedades atuais.

A internacionalização está aliada à globalização, aqui compreendida como fenômeno impulsionado por fatores econômicos, mas com fortes consequências sociais e culturais. Conforme aponta Jodelet (2017, p.485), 
A globalização e [com ela] as novas tecnologias de comunicação permitiram uma abertura para as músicas do mundo, que faz também da música uma experiência de outras partes. O valor simbólico dos gêneros, dos estilos e das formas, que demandam aprendizagens culturais, fazem dela um meio de identificação dos grupos e de manifestação e pertença social ou cultural.

Isso traz consigo uma aparente quebra de fronteiras, ocasionada pelos avanços tecnológicos ligados aos meios de produção diversos, desde a indústria e o comércio até as facilidades no acesso à informação, entre outros. Como resultado, ocorre a integração de comunidades, que passam a estar conectadas por novas "[...] combinações de espaço-tempo, tornando o mundo, em realidade e experiência, mais interconectado" (HALL, 2000, p.75).

Kertz-Welzel (2018) entende que as experiências cotidianas geradas por esse acesso fácil à informação e a conexões diversas entra em oposição aos grandes eventos mundiais voltados para a exploração de recursos naturais, guerras e perda de territórios, entre outros, e nos leva a uma dualidade entre aceitá-los e rejeitá-los.

Em 2002, Boaventura de Sousa Santos escreveu sobre a complexidade presente na relação de dualidade de Kertz-Welzel (2018), quando trata a globalização como

[...] um processo complexo que atravessa as mais diversas áreas da vida social, da globalização dos sistemas produtivos e financeiros à revolução nas tecnologias e práticas de informação e comunicação, da erosão do Estado Nacional e redescoberta da sociedade civil ao aumento exponencial das desigualdades sociais, das grandes movimentações fronteiriças de pessoas como emigrantes, turistas ou náufragos, ao protagonismo das empresas multinacionais e das instituições financeiras multilaterais, das novas práticas culturais e identitárias aos estilos de consumo globalizado. (SANTOS, 2002, p.11).

Um pouco antes, Stuart Hall (2000) chamava a atenção para a relação entre local e global em processos de interconexão e homogeneização, o que levou ao envolvimento de comunidades de todos os cantos do mundo, em realidade e experiências, voltando-se à mercantilização das culturas. Em obra escrita cinco anos mais tarde, Hall reafirma tal conceituação e a amplia, tratando da mercantilização da etnia e da alteridade.

Ao lado da tendência em direção à homogeneização global, há também uma fascinação com a diferença e com a mercantilização da etnia e da alteridade. Há, juntamente com o impacto "global", um novo interesse pelo "local". A globalização [...], na verdade, explora a diferenciação local. Assim, ao invés de pensar no global como "substituindo" o local, seria mais acertado pensar numa nova articulação entre "o global" e "o local" (HALL, 2005, p. 77).

Sobre o mesmo tema, Castro (2008) falava do processo de valorização financeira dos bens simbólicos e culturais, que passa a ser comandado pelos meios de comunicação e informação, financiados, em especial, pela indústria do turismo, que vê no ressurgimento das regionalidades um "nicho de mercado" até então pouco explorado. Pode-se dizer que seria a globalização do "local" via mercantilização, em especial da cultura 
e das culturas populares e, com elas, "as músicas". No campo de estudos da educação patrimonial, os patrimônios circundantes nesses espaços têm sido classificados como "patrimônios interessados".

A proposição apresentada por Kertz-Welzel (2018) sobre o modo como a globalização precisa ser encarada e absorvida é corroborada também por Santos (2002) quando propõe a reconstrução do conceito de globalização, sugerindo a luta contra o monoculturalismo autoritário, que desfavorece a coexistência de culturas ou que mercantiliza as culturas locais, em especial aquelas tidas como "exóticas".

Em Santos (2002) e mais tarde em Kertz-Welzel (2018), identificamos a proposta de uma globalização que considera, em seus processos, a luta pelo espaço para as minorias sociais, o que significa permitir, valorizar e ter em alta conta a presença de todos os tipos de cultura, de todos os sujeitos e toda forma de pensar, por mais distinta que possa parecer. Kertz-Welzel (2018) defende que, em busca disso, cabe a cada campo de conhecimento específico buscar estratégias, adequando suas formas de pensar e atuar com seus objetos de estudo, com vistas a suprir as necessidades iminentes.

Ou seja, é responsabilidade das áreas de conhecimento construir fundamentos e bases teóricas que possam dar suporte à sua atuação para atender às mudanças, seja dos próprios objetos, dos ambientes e/ou da relação dos sujeitos com os objetos. Com isso, permite-se que os processos de globalização e de internacionalização contribuam para uma educação musical mais conectada com as distintas realidades e necessidades do mundo contemporâneo, mormente ao tratar da constituição de seu patrimônio cultural, local e global.

Nessa direção é que Kertz-Welzel (2018) propõe um aparato teórico conceitual para tratar da globalização e da internacionalização no campo da educação musical, tendo como objetivo trazer contribuições para construir caminho na direção do que ela denomina comunidade global de educação musical culturalmente sensível.

A autora defende a ideia de que, mundialmente, como educadores musicais, já estamos conectados e somos parte de uma comunidade global de educação musical. Ela parte da ideia de que nossas práticas como educadores musicais, em qualquer lugar do mundo, convergem para algo que é comum - tratamos da relação das pessoas com músicas - e que está em uma estrutura de ação objetivamente globalizada. Porém, as formas de construir essas relações são diversificadas, estando esse fator na essência da construção teórica de cada campo do conhecimento em favor de seus objetivos (KERTZ-WELZEL, 2018).

Diante disso, a necessidade de questionar: qual tipo de comunidade global de educação musical estamos construindo? Concordamos com a autora quando argumenta sobre a necessidade de promover o desenvolvimento de uma comunidade global que reconheça a diversidade de práticas e de pesquisas na educação musical em contexto mundial, sendo este um dos fundamentos argumentativos do projeto de internacionalização aqui tratado.

Kertz-Welzel (2018) dirige a atenção para a "globalização" relacionando-a à ideia de criação de uma comunidade mundial, associada à construção de identidades, locais e globais, que estão em constante processo de mudança e, por isso, em constante bus- 
ca dessa identidade. Tal concepção vai ao encontro, também, da forma como é compreendida a educação patrimonial como campo de estudos sobre patrimônio cultural.

Compreendemos que o desenvolvimento de projetos pautados nos princípios apresentados permite maior aproximação e contribuição mais autêntica na construção de uma comunidade internacional de educação musical que seja culturalmente sensível. Defendemos que o projeto aqui apresentado vai ao encontro dessa demanda, por seu objetivo de adentrar contextos até então pouco ou ainda não explorados, em termos de trabalhos voltados para ações de estudos sobre educação patrimonial e internacionalização nas práticas de educação musical.

\section{Sobre a educação patrimonial}

A educação patrimonial vem sendo abordada por diferentes autores, em diversos campos de estudo, sob uma perspectiva educativa. Florêncio $(2015$, p.24) defende que

[...] a Educação Patrimonial deve ser tratada como um conceito basilar para a valorização da diversidade cultural, para a definição de identidades e de alteridades no mundo contemporâneo, e como um recurso para a afirmação das diferentes maneiras de ser e de estar no mundo. O reconhecimento desse fato, certamente, inserido em um campo de lutas e contradições, evidencia a visibilidade de culturas marginalizadas ou excluídas da modernidade ocidental, e que são fundamentais para o estabelecimento de diálogos interculturais e de uma cultura de tolerância com a diversidade.

Cantón (2009) reforça tal compreensão sobre educação patrimonial quando afirma que se trata de uma

[...] ação educativa consciente, organizada e sistematizada, dirigida à formação de sujeitos a partir do reconhecimento e da apropriação de seu sustento cultural, histórico, político e ético-espiritual. Ou seja, a partir do reconhecimento de suas particularidades e da apropriação plena, subjetiva e emancipadora de sua cultura, entendida como um sistema complexo de valores, crenças, tradições, costumes e horizontes utópicos constitutivos e constituintes de bens materiais e espirituais únicos, irrepetíveis e historicamente determinados. (CANTÓN, 2009, p.5, tradução nossa) $)^{4}$.

Ibarra (2016) e Ibarra, Bonomo e Ramirez (2014) corroboram com os conceitos apresentados, defendendo que tal sensibilização e valorização passam pelo conhecimento, sentido crítico, criatividade e responsabilidade sobre patrimônio cultural. E um dos caminhos apontados pelos autores é pelas ações que envolvem, de forma conjun-

4 [...] acción educativa consciente, organizada y sistematizada, dirigida a la formación de sujetos a partir del reconocimiento y la apropriación de su sustento cultural, histórico, político y ético-espiritual. Es decir a partir del reconocimiento de sus particularidades y de la apropriación plena, subjectiva y emancipadora de su cultura, entendida ésta como um complejo sistema de valores, creencias, tradiciones, costumbres, y horizontes utópicos constitutivos y constituyente de bienes materiales y espirituales únicos, irrepetibles e historicamente determinados (CANTÓN, 2009, p. 5). 
ta: a) a criação de estratégias de ensino e aprendizagem com e para os indivíduos, em especial os estudantes, como sujeitos ativos desse processo, que é de valorização, mas é também de construção de patrimônio cultural; e b) a organização da gestão do patrimônio cultural por parte das distintas comunidades, como a escolar. Nesse sentido, Fontal Merillas (2013) propõe que a educação patrimonial seja tratada com enfoque por meio do qual são construídos aportes que permitem que as pessoas compreendam patrimônio pela definição de estratégias de sensibilização em relação a patrimônio, seja ele individual e/ou coletivo, promovendo sua valorização e transmissão entre pessoas, grupos ou gerações (FONTAL MERILLAS, 2013). O ponto de partida é considerar que patrimônio constitui vínculos relacionados à atribuição de sentido e valor que pessoas estabelecem com bens, de toda e qualquer forma e origem.

Além disso, sua compreensão se prende ao fato de que todo vínculo sempre envolve pessoas. São as pessoas que, a seu tempo, criam, cuidam, selecionam, educam, transmitem e determinam valor ao patrimônio, gerando vínculos identitários e de pertencimento. Esses vínculos são a chave para que algo seja efetivamente transformado em patrimônio. Ou seja, o valor é determinado com base em critérios, por meio dos quais é possível compreender os valores atribuídos a "algo", seja individual ou coletivamente, em diferentes períodos.

De forma ampla, considerando os autores estudados, podemos dizer que a educação patrimonial possibilita às pessoas a capacidade de identificar e compreender seus patrimônios, individuais e/ou coletivos. Ela envolve processos de formação, estratégias e ações educativas ordenados de forma sistematizada, por meio de ações reflexivas e emancipadoras em distintos cenários: de educação formal, não formal ou informal. Suas práticas podem ser identificadas ou inseridas em ambientes escolares, familiares ou comunitários em geral, seja durante processos educacionais em tempo e espaço específicos, seja de forma livre, ao longo de toda a vida, de forma consciente ou não.

Assim, sua conceituação está associada às ações educativas voltadas para valorizar e construir as identidades que constituem os distintos povos e seus patrimônios, formados por processos de integração e agrupamento, em especial na contemporaneidade, dado o contexto de globalização, acesso à informação e processos de internacionalização com os quais convivemos.

Sob a perspectiva das políticas mundiais para a educação e cultura, em especial diante das demandas e mudanças das sociedades atuais e de seus processos de globalização e internacionalização, o campo da educação patrimonial vem ganhando território. Seu papel, como defendem Ibarra (2016) e Calaf e Fontal Merillas (2006), é fundamental na ordenação das ações educativas voltadas para o conhecimento, a compreensão, a valorização e a transmissão de patrimônios culturais.

A trajetória das políticas mundiais em torno de educação patrimonial permite dizer que, mesmo sem usar a terminologia, ela já estava presente nas políticas públicas de órgãos voltados ao estudo e à salvaguarda de patrimônio cultural desde a primeira metade do século XX. Por exemplo: no Brasil, o Iphan foi criado ainda na década de 1930. 
Nos últimos quase 50 anos, verificamos que as políticas mundiais em torno de ações educativas voltadas para patrimônio cultural têm se intensificado - em especial na Unesco, instituição de maior peso e recursos no que se refere ao patrimônio cultural em âmbito mundial e tida como um órgão regulador de políticas globais e locais, contando com 180 delegações permanentes em suas sessões de educação e de cultura (FONTAL MERILLAS, 2016).

Nas últimas décadas, o desenvolvimento das políticas internacionais voltadas para educação e cultura acabou impulsionando todo o movimento em torno da educação patrimonial, como constata García Valecillo (2015) quando diz que o crescimento de experiências voltadas para educação patrimonial teve início no final do século XX e foi expressivamente impulsionado nas primeiras décadas do século XXI. Como resultado, observam-se os avanços nas pesquisas e projetos desenvolvidos em todo o mundo que, por meio de estudos comprometidos, vêm contribuindo tanto na construção de um panorama sobre a educação patrimonial em realidades distintas quanto no desenvolvimento de bases teórico-metodológicas que sustentem a educação patrimonial como campo interdisciplinar de conhecimento.

É certo que muitas influências precisam ser consideradas nas distintas épocas e, em especial, no tempo presente. Como ensina Valecillo (2015), os processos de globalização e as políticas de desenvolvimento adotadas na atualidade têm transformado os espaços de relação entre as culturas, que levam as "identidades étnico-culturais" a interagir constantemente com a indústria cultural, com o consumo de bens culturais e com as tecnologias de informação e comunicação, construindo novos vínculos e atribuindo significados diversos ao patrimônio cultural.

Brandellero e Janssen (2014) trazem essa questão da indústria e comércio enfatizando o uso de patrimônio cultural como uma estratégia, que seria denominada "redescobrindo o local", o que, para as autoras, entra

[...] na esteira da globalização econômica e cultural, estimulando políticas de engajamento com a identificação social e cultural, dando origem a uma economia do patrimônio, na qual ele se torna um bem comercializável e instrumento para distinção e competitividade locais. (BRANDELLERO; JANSSEN, 2014, p.4-5, tradução nossa) $)^{5}$.

Tendo essas questões em mira, concordamos com Tolentino (2018) quando escreve sobre os cuidados necessários ao tratar da educação patrimonial, saindo em defesa de sua constituição em bases democráticas e dialógicas, contra a disseminação de uma visão instrutivista e opressora. Segundo o autor - e destacamos a importância desse fator quando se trata de formação docente -, há ainda uma "[...] série de conflitos, jogos de poder e acepções que envolvem a educação patrimonial" (TOLENTINO, 2018, p.40) que precisam ser debatidos e aprofundados para construir uma base teórica sólida para constituir seu campo.

5 In the wake of economic and cultural globalisation, spurring policies engaging with social cultural identification and giving rise to an economy of heritage, where heritage becomes a marketable commodity and tool for local distinction and competitiveness (BRANDELLERO et al. 2014, p.4-5). 


\section{Educação patrimonial na educação musical - um projeto de internacionalização}

A análise das ações deste projeto foi fundamentada no campo da educação patrimonial, lançando olhares sobre "patrimônio cultural" experienciado, concebido e compreendido em instâncias de interação pessoal e social, com a arte e com a cultura musical em contextos de internacionalização.

O projeto "Patrimônio cultural latino-americano - interface entre música, cultura popular e educação - Chile e Brasil - 2018" consistiu em uma ação de internacionalização entre a Universidade Estadual de Maringá e a Universidad de o'Higgins. Seus fundamentos foram pautados no campo da educação patrimonial, com base nos estudos da tese doutoral da professora brasileira atuante no projeto.

Desenvolvido em duas etapas - a primeira de abril a agosto de 2018 e a segunda durante o mês de janeiro de 2019 -, o projeto teve suas ações realizadas em diversas comunidades da VI Região do Chile, denominada Libertador General Bernardo O'Higgins. Contou com a participação efetiva de uma professora brasileira, docente da Universidade Estadual de Maringá, uma estudante do curso de Licenciatura em Música e um egresso, ambos da mesma instituição. Por parte da Universidad de O'Higgins, o projeto contou com a participação de dois integrantes da equipe de extensão para o planejamento, suporte técnico e auxílio no desenvolvimento geral. As ações foram destinadas a públicos variados: algumas voltadas para públicos específicos, como professores, músicos, agentes culturais, escolas e projetos comunitários; outras foram abertas para pessoas da comunidade em geral. A seguir, pontuamos a apresentação e discussão das ações.

O projeto teve início com visitas técnicas e observatórias realizadas em ambientes escolares e projetos comunitários, com o objetivo de identificar ações voltadas ao tema patrimônio cultural. Essas visitas permitiram mapear os estudos e práticas que têm como foco analisar o patrimônio cultural e identificar a forma como o patrimônio cultural é concebido nesses espaços. Foram visitadas 10 escolas, distribuídas em toda a região de O'Higgins/Chile; em quatro delas foram posteriormente realizadas atividades de oficina, participação em rodas de conversa ou apresentações musicais. No total, participaram das ações cerca de 1.200 pessoas, direta ou indiretamente.

Nesse momento exploratório pudemos identificar que o tema "patrimônio cultural" aparece com bastante frequência em projetos, programas de ensino de escolas e eventos comunitários regionais, talvez por influência da recente criação do "Ministerio de las Culturas, las Artes y el Patrimonio", em novembro de 2017, em cujas metas está a articulação com o Ministério da Educação no que se refere à criação de frentes de trabalho para atender às demandas dos espaços educativos diversos, dedicados ao estudo sobre patrimônio e diversidade cultural e fundamentados nos princípios estabelecidos pela Unesco.

Para conhecer as formas de pensar patrimônio cultural de participantes da comunidade, foram realizadas palestras e rodas de conversa na universidade, em escolas, em museus e em outros ambientes comunitários. Essas ações convergiram na aproximação da professora brasileira com a realidade das demais ações do projeto nos locais onde 
aconteciam, fortalecendo as ações no sentido de convergir aos temas de interesse e necessidades da comunidade local, no que se refere aos estudos de patrimônio cultural e suas musicalidades. Participaram dessas ações cerca de 350 pessoas, entre representantes de projetos, professores, diretores de escola e de museus, além de agentes comunitários diversos.

Com base nas conversas estabelecidas e nos interesses identificados, foram organizados cursos e oficinas de curta duração com o intuito de aproximação com as manifestações artísticas de culturas populares associadas ao patrimônio cultural imaterial brasileiro, porque este se mostrou um dos interesses quando da informação sobre a nacionalidade e a formação musical da professora brasileira atuante no projeto.

Foram oferecidos dois cursos em duas cidades da VI Região do Chile: Rancagua e San Fernando, com o objetivo de compartilhar patrimônios pela aproximação com as manifestações artísticas da cultura popular brasileira. As vivências com música e dança permitiram refletir sobre patrimônios, analisando as formas pelas quais nos identificamos, conhecemos e constituímos nosso patrimônio cultural local e latino-americano.

Os cursos tiveram carga horária de 20 horas, com encontros semanais de duas horas cada, para um total de 38 pessoas, sendo 24 em San Fernando e 14 em Rancagua. O público foi formado por pessoas com idade entre 15 e 62 anos e com experiências musicais variadas, uma vez que não houve pré-requisito para a participação, só vontade e disponibilidade de tempo. Além dos cursos, foram realizadas oficinas de curta duração em duas escolas e um projeto comunitário, todos com duração de duas horas. No total, participaram 72 estudantes, com idade entre 8 e 16 anos. Essas oficinas aconteceram nas comemorações da Semana del Patrimonio Cultural, comemorada ao final do mês de maio.

Esses espaços permitiram tratar patrimônio cultural por meio das práticas realizadas, identificando-as pelas perspectivas de como entendemos e o que conhecemos da "música do outro". Assim, foi possível refletir sobre os modos como constituímos nossos patrimônios, como nos relacionamos com outras culturas e práticas musicais e como essas práticas passam a integrar nosso patrimônio cultural.

A realização dos cursos gerou o interesse de compartilhar práticas, o que aconteceu via realização de intervenções artístico-didáticas em escolas, auditório universitário e ambientes comunitários diversos, com a participação dos dois intercambistas brasileiros com a professora e participantes dos cursos oferecidos. Foram realizadas cinco apresentações para um público total estimado em 980 pessoas.

De caráter didático, as apresentações contaram com repertório musical representativo das cinco regiões do Brasil. A proposta partiu de uma pergunta feita em uma aula do curso ministrado nas comunidades: “¿Que hay en Brasil además del Samba y de la Bossa Nova?". Durante o curso refletimos sobre os estereótipos que construímos sobre "a cultura do outro", que, nesse caso, também é nossa, coletiva, é latino-americana e a desconhecemos ou a compreendemos com base em valores limitantes e estereotipados. Assim, entendemos que tais ações tiveram uma construção positiva no sentido de acesso, conhecimento e fortalecimento de um patrimônio artístico cultural latino-americano. 
Adentrar o universo das culturas populares e dialogar sobre culturas num processo de intercâmbio aberto e participativo nos levou a desenvolver ações conjuntas, nas quais música e dança, brasileiras e chilenas, se encontraram em momentos de rico compartilhamento de práticas. Um desses momentos foi a realização de um encontro chamado "Oficina de dança - Brasil e Chile". O encontro aconteceu na cidade de San Fernando, com duração de quatro horas, nas quais foram compartilhadas danças dos dois países e teve como ministrante a professora brasileira e uma das participantes da oficina de música que estava em andamento. Participaram dessa ação um total de 16 pessoas. Desse encontro nasceram outras parcerias, culminando em formações e parcerias futuras entre os participantes.

Estar aberto a pessoas, propostas, ideias. Integrar-se, ensinar e permitir-se conhecer. Entendemos que esses sejam elementos centrais no processo de integração e construção conjunta de valores, conhecimentos e práticas nas atividades de internacionalização com vistas a constituir comunidades culturalmente sensíveis e globalmente integradas.

Outra frente de trabalho importante, nesse sentido, foi a participação em eventos comunitários e instâncias informais de convivência com as comunidades, envolvendo festas tradicionais, momentos de interação com grupos artísticos, rodas de música em espaços públicos e casas, eventos musicais comunitários, participação musical em apresentações informais, encontros para estudo de choro, samba e percussão brasileira, e uma prática compartilhada de estudo sobre o pandeiro brasileiro. Todos esses eventos foram realizados de maneira informal, sem a previsão de difusão aberta, daí não haver constado nas linhas gerais do projeto, porém é oportuno salientar a relevância de tais ações, uma vez que propiciaram outros modos de relação e aproximação com os sujeitos dos distintos grupos sociais. Essa aproximação foi considerada essencial no trato de ações de intercâmbio quando se tem "patrimônio cultural" como tema central.

A segunda etapa do projeto convergiu na realização da I Escuela de Educación Artística de la Universidad de O'Higgins, que teve a participação ativa da professora brasileira nas etapas de planejamento e integralização do evento. A escola aconteceu no modelo dos festivais de música brasileiros, adequando-se às necessidades e formas de organização comumente seguidas no Chile. Nesse evento, o projeto contou com a participação de outro professor da Universidade Estadual de Maringá, que ministrou um curso de Regência Musical. Ainda nesse evento, foi consolidada uma das mais importantes parcerias estabelecidas no projeto: a atuação conjunta entre a professora brasileira e uma professora e artista da comunidade de San Fernando, também autora deste artigo, que vinha desenvolvendo projetos voltados ao estudo de patrimônio cultural e artes, em especial com a música. Essa parceria foi resultado das ações de intercâmbios diversos, formais e informais, nas quais se abriu a oportunidade de conhecer o trabalho dos participantes, resultando em elaboração e oferta desse curso de maneira integrada.

O curso, que recebeu como título "Patrimonio Cultural Latinoamericano en la educación infantil: juego con música, cuerpo y movimiento", foi voltado para professores da Educação Infantil. De caráter prático, teve duração de 20 horas, distribuídas em quatro horas diárias, durante cinco dias. Como resultado, foi possível compartilhar, com os 
35 professores participantes, práticas e discussões acerca do tema patrimônio cultural na educação infantil, no contexto latino-americano, com amparo nas experiências e nos diálogos entre as duas professoras. Avaliamos que esse fator foi de fundamental importância para o enriquecimento das ações com o intuito de abrir olhares para diálogos internacionais, modos de ver e pensar patrimônio cultural em música, sob perspectivas diversas, culturais e locais.

Outro curso também ministrado pela professora brasileira durante o evento teve como tema as novas tecnologias e o ensino de música na escola atual. Teve duração de seis horas, distribuídas em dois dias e com a presença de 14 professores. $O$ tema resultou de um levantamento de interesses, realizado entre os professores participantes da pesquisa doutoral da professora brasileira e da vinculação do tema a projetos já desenvolvidos nesse sentido pela mesma professora.

A citada pesquisa doutoral também foi integrada ao projeto por meio do engajamento da universidade e de outras instituições locais, para disponibilizar espaços e contribuir na consolidação do grupo social chileno participante na investigação doutoral da professora brasileira. A investigação tem como objeto de estudos a educação patrimonial e sua relação com a atuação e formação docente em música.

Com o projeto ainda em andamento, como forma de levá-lo ao conhecimento da comunidade acadêmica latino-americana, aconteceu a apresentação e publicação em evento internacional, vinculado à ISME (Internacional Society for Music Educacion).

O projeto de internacionalização entre as duas instituições permitiu ainda a visita de um professor chileno à instituição brasileira, na qual ele foi convidado a participar de um Fórum de Educação Musical organizado pela Universidade Estadual de Maringá, ministrando cursos de curta duração para estudantes e pessoas da comunidade em geral sobre música de cultura popular chilena. Além disso, foram realizadas visitas técnicas à Reitoria, à Universidade da Terceira Idade e à Pró-reitora de Extensão e Cultura. Todas as atividades foram articuladas e conduzidas pela professora brasileira. Ainda nessa visita, foi feita uma inserção na TV Universitária de algumas cenas das práticas e repertórios desenvolvidos durante os cursos ministrados. Participaram dessas ações três estudantes do curso de Licenciatura em Música da Universidade Estadual de Maringá, um egresso e a professora brasileira que estava à frente do projeto.

$\mathrm{Na}$ interação pelas práticas artísticas dos sujeitos envolvidos, identificamos que os conhecimentos construídos de forma colaborativa sobre as culturas artístico-musicais de cada país e região nos permitiram avançar em termos reflexivos sobre como são vistos, entendidos e compartilhados os patrimônios culturais diversos.

Identificamos também que, ao tratar de música, o tema patrimônio cultural geralmente aparece nos discursos de forma condicionada ao repertório musical, que, por sua vez, está inserido nas práticas de cultura popular, sempre relacionadas ao folclore, seja ele local ou global.

Nesse caso, a experiência de internacionalização nos permitiu observar que se trata de um tema que vem sendo abordado de forma aproximada nos diferentes contextos sociais envolvidos nas ações, tanto no Brasil como no Chile. As concepções sobre 
patrimônio cultural, impressas no modo de atuar, falar, interagir e propor práticas musicais, por parte dos participantes das distintas atividades desenvolvidas no decorrer do projeto de internacionalização, nos permitem dizer, com fundamento nos preceitos da educação patrimonial, que há um longo caminho a ser percorrido para construir comunidades globais culturalmente sensíveis. Esses caminhos exigem que se amplie a compreensão sobre o que seja patrimônio cultural na sociedade contemporânea globalizada e internacional.

No que se refere às práticas musicais, questionamos: de que forma podemos contemplar a abertura de olhares para os distintos modos de relacionamento com patrimônio cultural em música ou mesmo para os diferentes tipos de patrimônio musical presentes nas sociedades atuais?

Em todas as experiências citadas, nos chamam a atenção a busca e o interesse dos participantes, que, em nossa análise, ressaltam a necessidade de ampliar os espaços de formação e discussão em torno da relação patrimônio, artes, músicas e culturas. Nesta direção, identificamos que as ações desenvolvidas no projeto reforçaram a urgência em ampliar instâncias formativas e buscaram integrar-se ou engajar-se na luta por políticas nacionais e locais voltadas à implantação de ações em educação patrimonial, em especial aquelas voltadas para o fortalecimento das identidades locais e suas relações com as dinâmicas globais envoltas em nossas sociedades contemporâneas. Desta forma - e voltando-nos para nosso objeto específico de estudos, a dizer, a música -, ressaltamos mais uma vez a importância do estabelecimento de comunidades globais de educação musical culturalmente sensíveis, atentas às demandas e engajadas politicamente.

Assim - em se tratando de contextos latino-americanos -, damos vistas às ações de internacionalização, pois estas se configuram como oportunidade de atender aos desafios da contemporaneidade no sentido de abrir olhares para a interculturalidade como caminho para uma educação patrimonial, artística e musical decolonial - considerando, grosso modo, no cerne da ideia de decolonialidade, a crítica ao eurocentrismo e às dinâmicas gerais do colonialismo, apoiando-se especialmente na ideia de decolonização dos saberes, conforme defendido por autores como Gomes (2018), Walsh (2017), Miranda (2017), Dussel (2016), Quijano (2014), Maldonado-Torres (2007), Lander (2005), dentre outros. Neste sentido, coincide com o pensamento de Walsh (2012, p.62, tradução nossa) quando afirma:

[...] entender a diferença étnico-racial-cultural como parte cêntrica - e como construção - desta aspiração, emergência e imposição é levar a discussão sobre a interculturalidade a terrenos que, por necessidade, se entrelaçam com assuntos de luta, poder e (de)colonialidade .

As experiências desenvolvidas no projeto apresentado evidenciam projetos de internacionalização desenvolvidos em contexto latino-americano, reforçando a necessi-

6 [...] entender la diferencia étnico-racial-cultural como parte céntrica - y como construc ^ción - de esta aspiración, emergencia e imposición, es llevar a la discusión sobre la interculturalidad a terrenos que, por necesidad, la entreteje con asuntos de lucha, poder y (de)colonialidad (WALSH, 2012, p. 62). 
dade de ações e reflexões pautadas nos princípios da decolonialidade. Nesse sentido, enxergamos a interculturalidade, com olhares do local para o global, como possibilidade de (re)conhecimento, compreensão e fortalecimento de uma cultura latino-americana diversa e decolonializada.

Entendemos aqui uma importante relação entre as ideias de identidade e diferença. Concordamos com Hall (2005) quando esclarece que as identidades são construídas e moldadas de acordo com o movimento das sociedades ante a diversidade, levando o conceito de identidade a um nível de complexidade e compreensão ainda em fase de exploração e (re)conhecimento na contemporaneidade.

Nesse sentido, entendemos que um dos caminhos primários esteja em desenvolver a sensibilidade às diferenças. Aqui se encontra o papel crucial da educação: pelo trabalho em prol do rompimento das possíveis barreiras colocadas em torno das diversidades (VEBER, 2020). Sobre isso, Akkari (2015, p.162) ensina:

A diversidade cultural na educação é um desafio internacional, não apenas porque a maioria das sociedades humanas é culturalmente diversa, mas também porque tal diversidade, se não for valorizada e tratada no sistema educacional, pode resultar em tensões e ameaças à coesão social.

Durante séculos, a América Latina recebeu povos dos mais diversos cantos do mundo, trazendo consigo suas culturas. Essa diversidade de povos é o que hoje constitui nossa identidade latino-americana. Porém, historicamente, a construção dessa identidade vem passando por processos de transformação em meio a um combate contra a dominação das epistemologias dominantes. Nesse sentido, em Santos e Meneses (2009) identificamos o reconhecimento de uma diversidade epistemológica e defesa do que é intitulado como "epistemologias do Sul"7.

Ao defender a criação do que chama de epistemologias do Sul, Boaventura de Sousa Santos propõe a reparação dos impactos e danos causados pelo capitalismo no movimento de colonização mundial. Tolentino $(2018$, p.46) concorda, nos seguintes termos:

[...] trata-se de uma alternativa que congrega um conjunto de intervenções epistemológicas que denunciam a supressão dos saberes empreendida pelos processos de colonização, a partir de uma norma epistemológica dominante, que se impõe como superior e se apresenta universal e naturalizada ao longo dos últimos séculos. Essa nova forma de conceber a produção do conhecimento, de forma diferente, valoriza os saberes subalternos que resistiram aos processos colonizadores e as reflexões por eles produzidas, trabalhando na perspectiva da horizontalidade entre os diferentes conhecimentos.

7 Trata-se de, geograficamente, identificar o sul geográfico como as regiões e os países que foram submetidos ao colonialismo europeu e que não atingiram níveis de desenvolvimento econômico e/ou social compatíveis com os demais países do mundo. Essa situação imprimiu a tais países a posição de dominados, ante a postura dominante de seus colonizadores, imposta por sua força militar, política e econômica, possibilitando, como afirma Tolentino (2018, p.56), a supremacia de uma "epistemologia ocidental", impondo-se sobre os povos e culturas não ocidentais e não cristãos, constituindo-se, assim, um epistemicı dio relacionado aos saberes e conhecimentos de grupos sociais subalternos e oprimidos. 
Ainda, para fortalecer o reconhecimento das diferenças e da diversidade com base na valorização das culturas dos povos historicamente dominados, em 2009 Nelson Maldonado-Torres defendia o que chamou de "esquecimento da colonialidade" para romper radicalmente a postura que ele considera como reprodutora da colonialidade. Ou seja, romper com os processos de legitimação das raízes europeias e sair em defesa de epistemologias não europeias, fortalecendo um processo de decolonialização.

A professora e pesquisadora Catherine Walsh, militante da corrente decolonial, trata em suas diversas obras da valorização das diversidades numa postura aberta à interculturalidade, defendendo-a como possibilidade para enfrentar o colonialismo ainda fortemente presente nos países colonizados (WALSH, 2017, 2012, 2009).

A defesa da autora pela "decolonialidade", em lugar da "descolonialidade", aparece como forma de construir relações de respeito e valorização das diversidades, no sentido de congregar todas as diferenças e influências que comportam nossas culturas, o que exige a transformação das estruturas sociais e políticas no que se refere aos seus modos de viver, pensar e construir identidades. Para ela, suprimir o "s" da palavra "descolonial" e tratar do termo "decolonial" não significa promover um anglicismo. Como afirma,

[...] não podemos simplesmente desarmar, desfazer ou reverter o colonial; ou seja, passar de um momento colonial a um não colonial, como se fosse possível que seus padrões e marcas deixassem de existir. A intenção é mesmo assinalar e provocar um posicionamento - uma postura e atitude contı冈nua - de transgredir, intervir, insurgir e incidir. O decolonial denota, portanto, um caminho de luta contínua no qual podemos identificar, visibilizar e estimular "lugares" de exterioridade e construções alternativas. (WALSH, 2009, p.16-15).

Considerando a argumentação de Walsh (2009), os estudos contemporâneos sobre a decolonialidade (GOMES, 2018; WALSH, 2017; MIRANDA, 2017; DUSSEL, 2016; QUIJANO, 2014; MALDONADO-TORRES, 2007; LANDER, 2005) e a análise das vivências apresentadas, corroboramos com a ideia de uma "Educação Patrimonial decolonial" que seja tratada como um projeto ético-político e social (TOLENTINO, 2018) - projeto este engajado nas lutas contínuas por processos de identificação de patrimônios pela integração de saberes e fazeres, com vistas à valorização de identidades individuais e coletivas.

Neste sentido, o suporte da educação patrimonial estaria - desde o universo conceitual às práticas educativas diversas - na sensibilização cultural pautada nas relações entre pessoas, contextos, patrimônios e - para retomar o objeto central deste estudo - músicas.

\section{Considerações finais}

As reflexões despertadas pelo projeto de internacionalização aqui apresentado nos permitiram identificar pontos nos quais nossos olhares convergem para a necessidade de fortalecê-lo como área em termos mundiais, formando, conforme propõe Kertz-Welzel (2018), uma comunidade de educação musical que esteja internacionalizada e que seja culturalmente sensível. 
O modo como o projeto foi implementado nos permitiu sintonizar com a ideia de que, no campo da educação, a internacionalização indica a expansão das fronteiras nacionais no que se refere ao compartilhamento de práticas, experiências e pesquisas. Quando partem de planejamento colaborativo que emerge da integração com as comunidades participantes, essas práticas, experiências e pesquisas permitem dizer que a internacionalização se consolida num processo educativo de construção, identificação e valorização de patrimônios que rompem fronteiras. No presente caso, com foco na proposta de integrar realidades e realizar intercâmbios igualitários, fortalecendo a ideia de construir uma comunidade internacional latino-americana que seja culturalmente sensível, dinâmica e aberta aos diálogos internacionais, essa ideia pode tornar-se mais efetiva quando, partindo da valorização e do (re)conhecimento local, se integra ao cenário mundial e intercontinental.

Compreendemos a necessidade de integrar suas práticas aos processos culturais diversos, assumindo as diversidades - desde as práticas locais até as influências externas - de forma equilibrada nos projetos de trabalho, possibilitando os processos de patrimonialização das musicalidades. Tratamos de patrimonialização desde a perspectiva contemporânea do campo da educação patrimonial, para o qual o termo remete à construção e à identificação de patrimônios culturais pelo estabelecimento de vínculos. Reforça-se que, nesta linha de pensamento, esses vínculos são constituídos pela combinação entre sentido e valor atribuídos "a algo" por grupos sociais ou indivíduos (GÓMEZ-REDONDO; FONTAL MERILLAS; IBÁÑEZ-ETXEBERRIA, 2016; FONTAL MERILLAS, 2016, 2013; IBARRA; BONOMO; RAMIREZ, 2014).

Sob os fundamentos apresentados, defendemos que implementar práticas e projetos de patrimonialização das experiências musicais sob uma visão decolonial vai ao encontro da possibilidade de criar, defender e fortalecer tanto as práticas locais quanto os processos migratórios e a expansão de fronteiras decorrentes do movimento de globalização e internacionalização.

Ou seja, a proposta de uma educação patrimonial decolonial vai ao encontro da necessidade de propor estratégias de ação focadas em fortalecer o papel de cada elemento cultural/musical presente em nossas sociedades, pela criação de vínculos independentemente das fronteiras geográficas ou políticas preestabelecidas. Desta forma, alinha-se ao movimento de internacionalização embasado nas políticas mundiais vigentes, que têm aberto caminhos para implementar ações focadas na integração de comunidades, de conhecimentos e práticas pela valorização da diversidade cultural e equidade voltadas para atender as necessidades da sociedade contemporânea. 


\section{Referências}

BRANDELLERO, A. et al. Popular music as cultural heritage: scoping out the field of practice. International Journal of Heritage Studies, v. 20, n. 3, p. 224-240, 2013. Disponível em: http://bit.ly/2YpurC9. Acesso em: 30 abr. 2019.

CALAF, R.; FONTAL MERILLAS, O. (coord.). Miradas al patrimonio. Gijón: Ediciones Trea, 2006. Disponível em: http://bit.ly/20j82GB. Acesso em: 12 jun. 2019.

CANTÓN, V. La Educación Patrimonial, como estrategia para la formación ciudadana. Correo del Maestro, Monterey, México, n. 154, marzo 2009. Disponível em: http://bit. ly/2QQ0hr5. Acesso em: 15 jul. 2019.

CASTRO, J. R. B. As festas em louvor a São João Batista na Bahia: práticas devocionais e elementos míticos na interface sagrado/ profano. In: SERPA, A. (org.). Espaços culturais: vivências, imaginações e representações. Salvador: EDUFBA, 2008. p. 181-197.

DUSSEL, E. Transmodernidade e interculturalidade: interpretação a partir da filosofia da libertação. Revista Sociedade e Estado, v. 31, n. 1, p. 51-73, jan./abr. 2016.

FLORÊNCIO, S. R. R. Educação patrimonial: um processo de mediação. In: TOLENTINO, Á. B. Educação patrimonial: reflexões e práticas. João Pessoa: IPHAN, 2012. p. 22-29.

FONTAL MERILLAS, O. Educación patrimonial: retrospectiva y prospectivas para la próxima década. Estudios Pedagógicos, v. 42, n. 2, p. 415-436, 2016. Disponível em: http://bit.ly/2SFt80z. Acesso em: 20 maio 2019.

FONTAL MERILLAS, O. (coord.). La Educación Patrimonial: del patrimonio a las personas. Gijón: Ediciones Trea, 2013. Disponível em: https://bit.ly/2Tdkbw4. Acesso em: 14 jun. 2019.

GARCÍA VALECILLO, Z. La educación patrimonial: Retos y pautas para educar a la ciudadanía desde lo patrimonial en Latinoamérica. CABÁS, n. 14, p. 58-73, 2015. Disponível em: http://bit.ly/2JTNPmq. Acesso em: 19 jun. 2019.

GOMES, N. L. O Movimento Negro e a intelectualidade negra descolonizando os currículos. In: BERNARDINO-COSTA, J.; MALDONADO-TORRES, N.; GROSFOGUEL, R. (org.). Decolonialidade e pensamento afrodiáspórico. Belo Horizonte: Autêntica, 2018. p. 223-246.

HALL, S. A identidade cultural na pós-modernidade. 4. ed. Rio de Janeiro: DP\&A, 2005. 
HALL, S. El trabajo de la representación. Lima: IEP - Instituto de Estudios Peruanos, 2002.

IBARRA, M. Patrimônio e comunidade. Perspectiva da educação patrimonial Chilena (1970-2015). Mouseion, Canoas, n. 23, p. 15-40, abr. 2016. Disponível em: https:// revistas.unilasalle.edu.br/index.php/Mouseion/article/view/2788. Acesso em: 20 mar. 2019.

IBARRA, M.; BONOMO, U.; RAMIREZ, C. El patrimonio como objeto de estudio interdisciplinario: Reflexiones desde la educación formal chilena. Polis, Santiago, v. 13, n. 39, p. 373-391, dic. 2014. Disponível em: http://bit.ly/30XjLvU. Acesso em: 12 mar. 2019.

JODELET. D. Representações sociais e mundos de vida. São Paulo: Fundação Carlos Chagas; Curitiba: PUCPress, 2017.

KERTZ-WELZEL, A. Globalizing Music Educacion: A Framework. 1 ed. Indiana: Indiana University Press, 2018.

LANDER, E. et al. A colonialidade do saber: eurocentrismo e ciências sociais.

Perspectivas latino-americanas. Buenos Aires: CLACSO, 2005.

MALDONADO-TORRES, N. Sobre la colonialidad del ser: contribuciones al desarrollo de un concepto. In: CASTRO-GÓMEZ, S.; GROSFOGUEL, R. El giro decolonial.

Reflexiones para una diversidad epistémica más allá del capitalismo global. Colombia: Siglo del Hombre, 2007. p. 127-167.

MIRANDA, C. Clandestinización y re-existencia diaspórica: horizontes expedicionários e insurgencia en afroamérica. In: SEPTIEN, R. C.; BIDASECA, K. et al. Más allá del decenio de los pueblos afrodescendentes. Buenos Aires: CLACSO, 2017.

QUIJANO, Aníbal (ed.). Des/colonialidad y bien vivir: un nuevo debate en America Latina. Lima: Editorial Universitaria, 2014.

SANTOS, B. de S. A crítica da razão indolente: contra o desperdício da experiência. 4. ed. São Paulo: Cortez, 2002.

TOLENTINO, Á. B. Educação Patrimonial decolonial: perspectivas e entraves nas práticas de patrimonialização federal. Revista Sillogés, v. 1, n. 1, p. 41-60, jan./jul. 2018. Disponível em: https://bit.ly/3noMvsr. Acesso em: 10 dez. 2020. 
WALSH, C. Pedagogías decoloniales: prácticas insurgentes de resistir, (re)existir y (re) vivir. Tomo II. Quito, Ecuador: Abya-Yala, 2017. Disponível em: https://ayalaboratorio. com/2018/03/31/catherine-walsh-pedagogias-decoloniales-praticas-insurgentes-deresistir-reexistir-e-reviver/. Acesso em: 10 dez. 2020.

WALSH, C. Interculturalidad y (de)colonialidad: perspectivas críticas y politicas. Visão Global, Joaçaba, v. 15, n. 1-2, p. 61-74, 2012. Disponível em: http://bit.ly/2K8Em9R. Acesso em: 16 jan. 2019.

WALSH, C. Interculturalidad, Estado, Sociedad: luchas (de)coloniales de nuestra época. Quito: Universidad Andina Simón Bolívar; Abya-Yala, 2009. 
